\title{
$N$-Ethylbenzylammonium Fluorochromate (VI) Adsorbed on Silica Gel, a Mild and Selective Heterogeneous Reagent
}

\author{
S. Zahra Sayyed-Alangi* and Mohammad T. Baei
}

Islamic Azad University, Azadshahr Branch, Department of Chemistry, Azadshahr, Golestan, Iran. Tel. (+98)1722240194, Fax. (+98)1746724003. zalangi_szalangi@yahoo.com

Received July 12, 2010; Accepted September 8, 2010

\begin{abstract}
A mild and selective method for the oxidation of primary and secondary alcohols to their corresponding aldehydes and ketones with $N$-ethylbenzylammonium fluorochromate (VI), EBAFC, is reported. Stability, reaction rate, ease of work-up and efficiency of the EBAFC are considerably increased upon its adsorption on silica gel. The $N$-ethylbenzylammonium fluorochromate (VI) adsorbed on silica gel is inert to aldehydes, ketones, oximes, thiols, sulfides, phenols, pyrans, trimethylsilanes, malonates and thioacetamides.

Keywords: $N$-ethylbenzylammonium Fluorochromate (VI), Heterogeneous Oxidant, Alcohols, Aldehyde, Ketone.
\end{abstract}

\section{Introduction}

In modern organic synthesis the oxidation of an organic substrate in anhydrous and aprotic solvent, under mild and neutral conditions is important [1]. Therefore, synthetic organic chemists pay attention to search for new oxidizing reagents. In recent years, investigators have been looking for the preparation of oxidants with a number of characteristics including lower cost, higher yields, better selectivity, performing in mild and neutral conditions, easy preparation, low toxicity and short reaction times. Extensive works have led to the development of a good number of chromium (VI) oxidizing agents such as pyridinium fluorochromate (PFC) [2, 3], pyridinium chlorochromate (PCC) [4], pyridinium dichromate (PDC) [5], 2,2'-quinolinium fluorochromate (QFC) [6], poly [vinyl (pyridinium fluorochromate)] [7], isoquinolinium fluorochromate (IQFC) [8], 3,5-dimethylpyrazolium fluorochromate (DmpzHFC) [9], 2,6-dicarboxypyridinium chlorochromate [10, 11], tetramethylammonium fluorochromate (TMAFC) [12], tetrabutylammonium fluorochromate (TBAFC) [13], morpholinium chlorochromate (MCC) [14], trialkylammonium fluorochromate [1], benzyltrimethylammonium fluorochromate [15], tripropylammonium fluorochromate [16], benzimidazolium fluorochromate [17], and benzyltriethylammonium chlorochromate [18], etc. Moreover, we have recently reported two new reagents as $N$-methylbenzylammonium fluorochromate (MBAFC) [19] and morpholinium fluorochromate [20] for the oxidation of alcohols. All these reagents are mostly used for the oxidation of alcohols to the corresponding aldehydes and ketones.

On the other hand, medicinal chemists in the pharmaceutical industry routinely make use of solid-phase organic synthesis (SPOS) to prepare libraries of small organic molecules for screening [21]. These techniques can be attractive and suitable
Resumen. Se describe un método suave y selectivo para la oxidación de alcoholes primarios y secundarios a sus aldehídos y cetonas correspondientes, con el fluorocromato de N-etil bencil amonio (FCEBA). La estabilidad, la velocidad de la reacción, la facilidad en el trabajo de la reacción y la eficiencia del FCEBA se incrementan considerablemente cuando este reactivo se adsorbe sobre gel de sílice. El fluorocromato de N-etil bencil amonio (VI) adsorbido sobre gel de sílice es inerte con aldehidos, cetonas, oximas, tioles, sulfuros, fenoles, piranos, trimetilsilanos, malonatos y tioacetamidas.

Palabras clave: Fluorocromato de $N$-etil bencil amonio (VI), Oxidantes heterogéneos, Alcoholes, Aldehídos, Cetonas.

for oxidations of organic substrates. With this method, the oxidations often occur with high yields and the work-up involves simple filtration and evaporation of the solvent. For example, yields have been increased for the oxidation of alcohols by using PCC on alumina [22] instead of only PCC. In this case, Alumina is used as a solid-phase.

This work reports the $N$-ethylbenzylammonium fluorochromate (EBAFC) adsorbed on silica gel as a new promising reagent, which improves efficiency, selectivity, reaction rate, and stability, for the oxidation of alcohols to their corresponding aldehydes and ketones under mild and neutral conditions.

\section{Results and Discussion}

We are reporting the synthesis of $N$-ethylbenzylammonium fluorochromate EBAFC, adsorbed on wet $\mathrm{SiO}_{2}(50 \%$ w/w) and the reaction with primary and secondary alcohols (1) in hexane to their corresponding aldehydes and ketones (2), (Scheme 1). These oxidations take place under mild and completely heterogeneous conditions giving good yields, (Table 1). Moreover, this oxidant is inert to aldehydes, ketones, oximes, thiols, sulfides, phenols, pyrans, trimethylsilanes, malonates and thioacetamides.

The EBAFC is easily synthesized in a relatively good yield, (78\%). The synthesis is carried out from the reaction of $\mathrm{CrO}_{3}$ with aqueous $\mathrm{HF}$ and $N$-ethylbenzylamine, in the molar ratio of 1:1.5:1. The reagent is obtained as an orange solid and elemental analyses, IR and NMR spectroscopy recognize its structure. In the IR spectrum, two absorptions at 905 and 940 $\mathrm{cm}^{-1}$ appear due to $\mathrm{Cr}-\mathrm{O}$ bond, together with a $\mathrm{Cr}-\mathrm{F}$ band at $640 \mathrm{~cm}^{-1}$. The NMR data are in agreement with the EBAFC structure. Moreover, the ${ }^{19} \mathrm{~F}$ NMR of this reagent shows a typical absorption at $-132.09 \mathrm{ppm}$. The EBAFC is soluble in 
<smiles>[R]C([R])=O</smiles>

Scheme 1.

solvents such as acetonitrile, DMF, acetone and chloroform, is less soluble in dichloromethane, dioxane and THF and not soluble in $n$-hexane.

The heterogeneous reaction mixtures are thoroughly stirred, for 22-59 min, at room temperature. During the reaction, the color of reagent changes from orange to brown, providing visual evidence for ascertaining the progress of the oxidation. The corresponding products, aldehyde or ketone (2) can be easily isolated by a simple filtration and evaporation of the solvent. In comparison to reported oxidants, the EBAFC adsorbed on wet $\mathrm{SiO}_{2}(50 \% w / w)$ makes available relatively higher yields of products, in lower molar ratio and shorter reaction times (Table 1 ).

Oxidations may occur using only EBAFC, in the absence of wet $\mathrm{SiO}_{2}$, but considerable improvement of both yields and reaction times are obtained in the presence of this adsorbent. The wet $\mathrm{SiO}_{2}$ (solid-phase) may act as a reaction medium, providing an effective heterogeneous surface for the oxidation and at the same time making an easy work-up.

Relatively higher conversions of primary and secondary alcohols (1) to their corresponding aldehydes and ketones (2) are obtained via EBAFC adsorbed on wet $\mathrm{SiO}_{2}$, (Table 1). For example, yields obtained from the oxidation of 4-chlorobenzyl alcohol $95 \%$, benzyl alcohol 92\% (reported 90\%) [2, 3], and cyclohexanol 91\% (reported 89\%) [2, 3] are obtained. Neither carboxylic acids nor other by-products are formed upon oxidation of alcohols using this reagent. Moreover, this reagent does not oxidize a large variety of other substrates, including benzylaldehyde, acetophenone, diphenyl sulfide, thiophenol,

Table 1. Oxidations via EBAFC/silica gel, EBAFC, $\mathrm{PFC}^{\mathrm{a}}$ and $\mathrm{IQFC}^{\mathrm{b}}$.

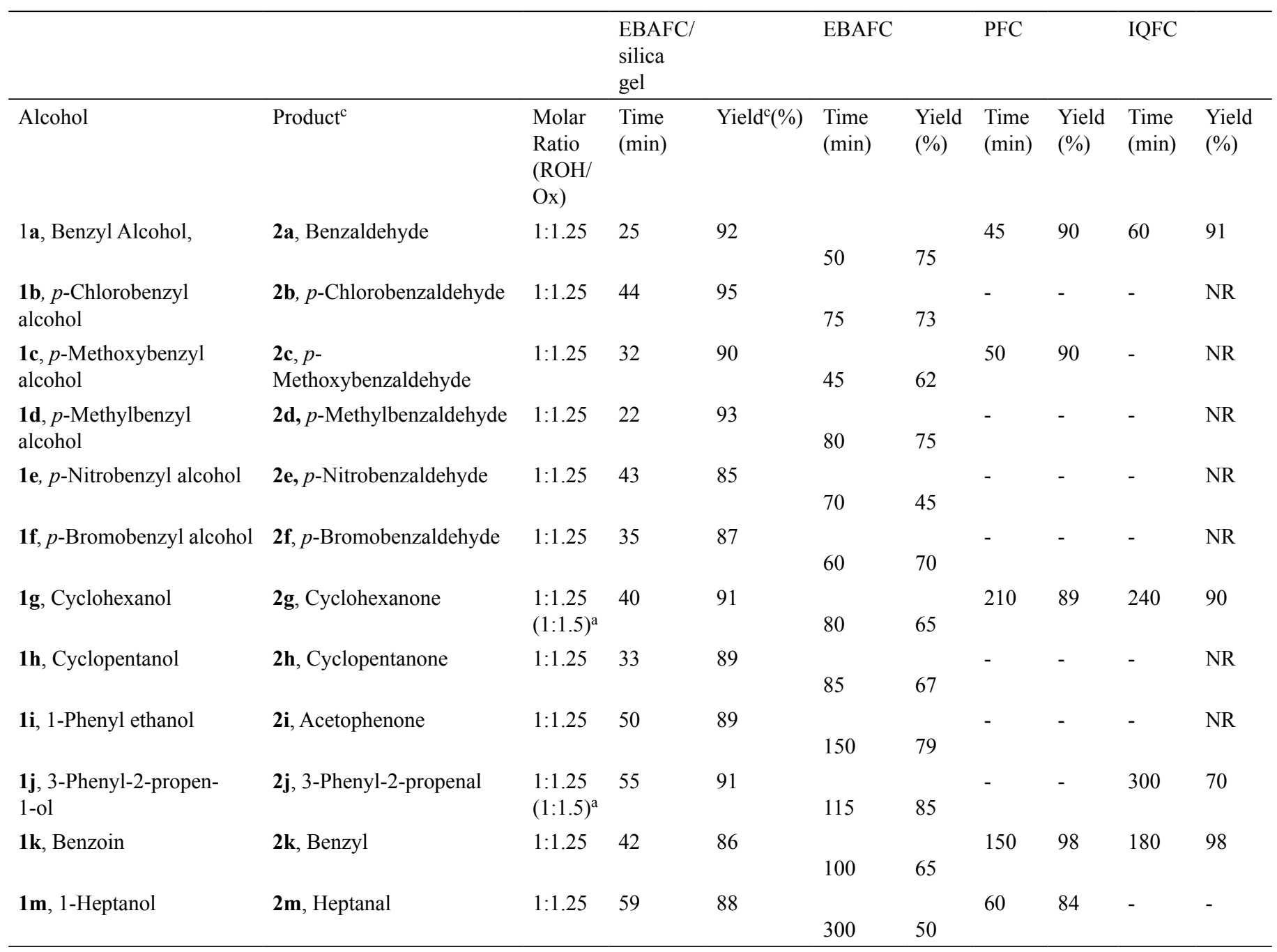

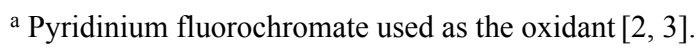

${ }^{\mathrm{b}}$ Isoquinolinium fluorochromate used as the oxidant [8].

${ }^{\mathrm{c}}$ Products were characterized by comparison with authentic samples (NMR, IR, TLC and mp/bp measurement). 
3,5-dimethoxyphenol, 2-benzyl-3,4-dihydro-2H-pyran, benzyloxytrimethylsilane, $\mathrm{N}$-methyl-2-phenylthioacetamide, 1-phenyl-ethanone oxime and sodium 2-hydroxyimino-malonate. Groups such as methoxy and methyl attached on the phenyl ring are inert to this oxidant. Thus, this oxidant can be used for the synthesis of highly functionalized molecules.

It has been found that this reagent has many advantages in comparison to similar oxidizing reagents, such as easier preparations, application to $\mathrm{pH}$ sensitive molecules, good selectivity in the reaction, high yields, short reaction times, lower oxidant/substrate ratio, lower solvent requirement, and simple work-up.

\section{Conclusion}

A new reagent, $N$-ethylbenzylammonium fluorochromate (VI) adsorbed on silica gel, EBAFC/wet $\mathrm{SiO}_{2}$, selectively oxidizes primary and secondary alcohols to the corresponding aldehydes and ketones. Many functional groups are inert towards this reagent, including aldehydes, ketones, oximes, thiols, sulfides, phenols, pyrans, trimethylsilanes, malonates, and thioacetamides. It proves to be of low cost, readily available, easy synthesis and simple work-up. Its advantages include higher yields, shorter reaction times, better selectivity, application to $\mathrm{pH}$ sensitive molecules, performing in a lower oxidant/substrate ratio, and with lower solvent requirement.

\section{Experimental Materials and Methods}

$N$-ethylbenzylamine and chromium trioxide $\left(\mathrm{CrO}_{3}\right)$ were obtained from Fluka (Buchs, Switzerland). Melting points were measured on an Electro thermal 9100 apparatus. Elemental analyses were performed for $\mathrm{C}, \mathrm{H}$, and $\mathrm{N}$ using a Heraeus CHN-O-Rapid analyzer. IR spectra were recorded on a Bomen FT-IR-MB100 Spectrometer. ${ }^{1} \mathrm{H}$ NMR spectrum was recorded using $90 \mathrm{MHz}$ JEOL JNM-EX90A instrument. ${ }^{13} \mathrm{C}$ and ${ }^{19} \mathrm{~F}$ NMR spectra were determined on a BRUKER-DRX500 AVANCE instrument.

\section{Synthesis of $\mathrm{N}$-ethylbenzylammonium fluorochromate (VI)}

Chromium (VI) oxide $\left(\mathrm{CrO}_{3} ; 2 \mathrm{~g}, 0.02 \mathrm{~mol}\right)$ was dissolved in water $(5 \mathrm{~mL})$ in a polyethylene beaker and $40 \%$ hydrofluoric acid $(1.50 \mathrm{~mL}, 0.03 \mathrm{~mol})$ was added with stirring. After $5 \mathrm{~min}$, the homogenous solution was cooled to $0{ }^{\circ} \mathrm{C}$. $N$-ethylbenzylamine ( $3 \mathrm{ml}, 0.02 \mathrm{~mol})$ was carefully added over $10 \mathrm{~min}$. The resulting solution was stirred at $0{ }^{\circ} \mathrm{C}$ for $30 \mathrm{~min}$. An orange solid was obtained. The crystals were collected on a sintered glass funnel and dried in vacuum (Yield: $4.00 \mathrm{~g}, 78 \%$; mp 41$\left.42{ }^{\circ} \mathrm{C}\right)$. IR $v_{\max }(\mathrm{KBr}) 905,940,641 \mathrm{~cm}^{-1} ;{ }^{1} \mathrm{H} \mathrm{NMR}\left(\mathrm{CDCl}_{3}\right.$, $90 \mathrm{MHz}) \delta 1.34\left(3 \mathrm{H}, \mathrm{t}, \mathrm{CH}_{3}\right), 3.18\left(2 \mathrm{H}, \mathrm{q}, \mathrm{CH}_{2}\right), 4.20(2 \mathrm{H}, \mathrm{s}$, $\left.\mathrm{CH}_{2}\right), 4.99\left(2 \mathrm{H}, \mathrm{s}, \mathrm{NH}_{2}\right), 7.5(5 \mathrm{H}, \mathrm{s},-\mathrm{Ph}) .{ }^{13} \mathrm{C} \mathrm{NMR}\left(\mathrm{CDCl}_{3}\right.$,
$125 \mathrm{MHz}) \delta 10\left(-\mathrm{CH}_{3}\right), 42\left(-\mathrm{CH}_{2}-\mathrm{N}\right), 50\left(=\mathrm{C}-* \mathrm{CH}_{2}-\mathrm{N}-\right)$, 128-130 (-Ph). ${ }^{19} \mathrm{~F}$ NMR $\left(\mathrm{CDCl}_{3}, 470 \mathrm{MHz}\right) \delta$-132.09. Anal. C $42.35 \%$, H $5.49 \%$, N $5.49 \%$, Calcd for $\mathrm{C}_{9} \mathrm{H}_{14} \mathrm{NCrO}_{3} \mathrm{~F}, \mathrm{C}$ $42.12 \%$, H $5.35 \%$, N 5.26\%.

\section{General procedure for oxidation of alcohols with $\mathrm{EBAFC} /$ wet $\mathrm{SiO}_{2}$}

To a stirred suspension of EBAFC/wet $\mathrm{SiO}_{2}(0.5 \mathrm{~g}$ EBAFC: $0.5 \mathrm{~g}$ silica gel $/ 4$ drops $\left.\mathrm{H}_{2} \mathrm{O}\right)$ in $n$-hexane $(5 \mathrm{~mL})$, a solution of the alcohol in the minimum amount of $n$-hexane was added drop wise at room temperature, the molar ratio of alcohol to the oxidant being 1:1.25 (Table 1). The progress of the reaction was monitored by TLC (solvent, 5:1, $n$-hexane/ethyl acetate, $\mathrm{v} / \mathrm{v})$. The mixture was diluted with ether $(1: 1 \mathrm{vol} / \mathrm{vol})$ and was filtered through a short column of silica gel to give a clear solution. The solvent was evaporated and the products were purified by distillation, crystallization and/or column chromatography. Products were characterized by comparison with authentic samples (NMR, IR, TLC and $\mathrm{mp} / \mathrm{bp}$ measurement). Yields (\%) were obtained as isolated product and/or determined via NMR analyses (Table 1).

\section{Acknowledgments}

The authors would like to thank Dr. M. Z. Kassaee, H. SajjadiGhotbabadi and Dr. Mahmood Tajbakhsh for their helpful discussions.

\section{References}

1. Ghammami, S.; Khorsandtabar, S.; Moghimi, A.; Sahebalzamani, H. J. Mex. Chem. Soc. 2009, 53, 41-43.

2. Bhattacharjee, M. N.; Chaudhuri, M. K.; Purkayastha, S. Tetrahedron 1987, 43, 5389-5392.

3. Bhattacharjee, M. N.; Chaudhuri, M. K.; Dasgupta, H. S.; Roy N.; Khathing, D. T. Synthesis 1982, 588-590.

4. Corey, E. J.; Suggs, J. W. Tetrahedron Lett. 1975, 16, 2647-2650.

5. Corey, E. J.; Schmidt, G. Tetrahedron Lett. 1979, 20, 399-402.

6. Murugesan, V.; Pandurangan, A. Indian J. Chem. 1992, 31B, 377379.

7. Srinivasan; R.; Balasubramanian, K. Synth. Commun. 2000, 30(24), 4397-4404.

8. Srinivasan, R.; Stanley, P.; Balasubramanian, K. Synth. Commun. 1997, 27, 2057-2064.

9. Bora, U.; Chaudhuri, M. K. Tetrahedron 2001, 57, 2445-2448.

10. a) Tajbakhsh, M.; Hosseinzadeh, R.; Yazdani-Niaki, M. $J$. Chem. Res. 2002, 508-510; b) Hosseinzadeh, R.; Tajbakhsh, M.; Shakoori, A.; Yazdani-Niaki, M. Monatsh. Chem. 2004, 135, 1243-1249.

11. a) Hosseinzadeh, R.; Tajbakhsh, M.; Yazdani-Niaki, M. Tetrahedron Lett. 2002, 43, 9413-9416; b) Tajbakhsh, M.; Hosseinzadeh, R.; Shakoori, A. Tetrahedron Lett. 2004, 45, 18891893.

12. Mahjob, A. R.; Ghammami, S.; Kassaee, M. K. Tetrahedron Lett. 2003, 44, 4555-4557.

13. Ghammami, S.; Seyed Sajadi, S. A. J. Serb. Chem. Soc. 2005, 70, 1243-1248. 
14. a) Malani, N.; Baghmar, S. P.; Sharma, P. K. Indian J. Chem. 2008, 47A, 1373-1376; b) Choudhary, A.; Agarwal, S.; Sharma, V. Indian J. Chem. 2009, 48A, 362-366; c) Shiekh, H. N.; Sharma, M.; Hussain, M.; Kolsorta, B. L. Oxid. Commun. 2005, 28, 887-893; d) Bishnoi, G.; Malani, N.; Sindal, R. S.; Sharma, P. K. J. Indian Chem. Soc. 2007, 84, 892-896.

15. Kassaee, M. Z.; Hattami, M.; Moradi, M. Acta Chim. Slov. 2004, 51, 743-750.

16. Ghammamy, S.; Hashemzadeh, A. Bull. Korean Chem. Soc. 2004, $25,1277-1279$

17. a) Sivamurugan, V.; Abraham, Rajkumar G.; Arabindo, B.; Murugesan, V. Indian J. Chem. 2005, 44B, 144-147; b) Dharmaraja, J.; Krishnasamy, K.; Shanmugam, M. E-J. Chemistry 2008, 5, 754-760.

18. Ravdeep, K.; Neelam, S.; Vinita, S. Indian J. Chem. 2006, 45A, 2441-2445.
19. Kassaee, M. Z.; Sayyed-Alangi, S. Z.; Sajjadi-Ghotbabadi, H. Molecules 2004, 9, 825-829.

20. Sayyed-Alangi, S. Z.; Sajjadi-Ghotbabadi, H.; Baei, M. T.; Naderi, S. E-J. Chemistry accepted.

21. a) Gordon, E. M.; Barrett, R. W.; Dower, W. J.; Fodor, S. P. A.; Gallop, M. A. J. Med. Chem. 1994, 37, 1233-1251; b) Gordon, E. M.; Barrett, R. W.; Dower, W. J.; Fodor, S. P. A.; Gallop M. A. J. Med. Chem. 1994, 37, 1385-1401; c) Fruchtel, J. S.; Jung, G. Angew. Chem. Int. Ed. Engl. 1996, 35, 17-42; d) Hermkens, P. H. H.; Ottenheijm, H. C. J.; Rees, D. Tetrahedron 1996, 52, 45274554; e) Terrett, N. K.; Gardner, M.; Gordon, D. W.; Kobylecki, R. J.; Steele, J. Tetrahedron 1995, 51, 8135-8173; f) Thompson, L.; Ellman, J. A. Chem. Rev. 1996, 96, 555-600.

22. a) Cheng, Yu-Shia; Liu, Wen-Liang; Chen, Shu-hsia. Synthesis 1980, 223-224; b) Sanjay, B.; Subrata, K. C. Tetrahedron 2003, $5,3493-3498$. 